\title{
ANALISIS PENANGANAN BANJIR DI JATIMULYA KABUPATEN BEKASI JAWA BARAT
}

\author{
Ir. Darmadi, MM. \& Ir. Darmojo
}

\begin{abstract}
Abstraksi
Jatimulya merupakan bagian wilayah Kabupaten Bekasi yang apabila terjadi hujan akan terjadi banyak genangan. Penyebab terjadinya genangan di wilayah Jatimulya ini disebabkan berubahnya fungsi lahan dari pertanian ke permukiman, adanya permasalahan pengaliran sungai (3 sungai) akibat penyempitan aliran karena adanya jembatan serta pendangkalan sungai karena sedimentasi serta sampah.

Dengan perhitungan hujan rencana Log Pearson III serta perhitungan debit rencana dengan rumus rasional, maka ditetapkan bahwa untuk saluran dipakai perencanaan banjir 50 tahunan dan bangunan air yang ada di dalamnya (jembatan, gorong, siphon serta box culvert) dipakai perencanaan banjir 100 tahunan.
\end{abstract}

Kata kunci : banjir rencana, genangan, 50 tahunan, 100 tahunan.

\section{Pendahuluan}

Daerah Jatimulya merupakan bagian dari Kabupaten Bekasi Jawa Barat, mempunyai luasan DAS sebesar 27,26 km². DAS seluas itu dibagi lagi menjadi sub DAS antara lain DAS Kali Pengasinan seluas 4,78 $\mathrm{km}^{2}$, DAS Kali Jatimulya seluas 6,13 $\mathrm{km}^{2}$, DAS Kali Menir seluas 3,64 km², DAS Kali Sepak seluas 12,70 $\mathrm{km}^{2}$.

Daerah Jatimulya merupakan daerah dataran rendah yang mempunyai permasalahan drainase yang cukup rumit. Banyak faktor yang mempengaruhi dan perlu pertimbangan yang matang dalam perencanaan, antara lain peningkatan debit, penyempitan dan pendangkalan saluran, reklamasi, amblesan tanah, limbah sampah dan pasang surut air laut. 
Sumber permasalahan utama di Jatimulya adalah peningkatan jumlah penduduk, baik akibat pertumbuhan penduduk asli maupun dari peningkatan urbanisasi. Peningkatan jumlah penduduk selalu diikuti dengan peningkatan infrastruktur kawasan, seperti perumahan, sarana transportasi, air bersih, pendidikan dan lain sebagainya. Peningkatan jumlah limbah baik limbah cair maupun padat juga menjadikan masalah besar dalam perencanaan drainase. Selain itu dengan perubahan tata guna lahan yang sangat pesat terutama yang menghilangkan daerah resapan atau daerah genangan banjir akibat perluasan hunian, menjadikan perencanaan drainase jadi semakin rumit.

Oleh sebab itu, dengan mengantisipasi semua itu maka dicoba untuk merencanakan kembali sistim drainase yang sudah ada walaupun dengan keterbatasan dana yang ada dan diupayakan mengurangi seoptimal mungkin akibat kegagalan drainase.

\section{Dasar Teori}

Dasar perencanaan untuk penanganan banjir di daerah Jatimulya ini mengacu pada desain untuk salurannya (sungainya) dan bangunan air yang ada di saluran tersebut. Kriteria yang digunakan untuk desain saluran adalah banjir 50 tahunan (Q50) dan untuk bangunan airnya (jembatan, gorong-gorong, siphon, talang air, tanggul, dsb.) digunakan banjir 100 tahunan (Q100).

Menurut CIDA (1994) dan Haskoning (1989), periode ulang atau banjir rencana untuk saluran, dapat menggunakan standard perencanaan seperti Tabel 1.

Tabel 1. : Standard Periode Ulang Untuk Perencanaan Saluran

\begin{tabular}{|c|c|c|c|c|c|}
\hline \multirow[t]{2}{*}{ No. } & \multirow[t]{2}{*}{ Klas Kota*) } & \multicolumn{4}{|c|}{$\begin{array}{c}\text { Luas Daerah Aliran Sungai (DAS) } \\
\text { dalam Ha }\end{array}$} \\
\hline & & $<10$ & $\begin{array}{l}10- \\
100\end{array}$ & $\begin{array}{c}100- \\
500\end{array}$ & $>\mathbf{5 0 0}$ \\
\hline 1. & Metropolitan & $1-2$ & $2-5$ & $5-10$ & $10-50$ \\
\hline 2. & Kota Besar $\left.{ }^{* *}\right)$ & $1-2$ & $2-5$ & $2-5$ & $5-25$ \\
\hline 3. & $\begin{array}{l}\text { Kota } \\
\text { Menengah }\end{array}$ & $1-2$ & $2-5$ & $2-5$ & $5-10$ \\
\hline 4. & Kota Kecil & $1-2$ & $1-2$ & $1-2$ & $2-5$ \\
\hline & $\begin{array}{l}*) \\
* *) \\
* * *)\end{array}$ & $\begin{array}{l}\text { berdas } \\
500.00 \\
<500 \text {. }\end{array}$ & $\begin{array}{l}\text { kepad } \\
-2.00 \\
0 \text { pen }\end{array}$ & $\begin{array}{l}\text { n pend } \\
00 \text { pen } \\
\text { uk }\end{array}$ & \\
\hline
\end{tabular}


Sedangkan untuk desain bangunan air, dapat digunakan standard perencanaan dari Dinas Pengairan (1989) seperti Tabel 2 berikut :

Tabel 2. : Standard Perencanaan Untuk Periode Ulang Bangunan Air

\begin{tabular}{|c|l|l|c|c|}
\hline No. & \multicolumn{1}{|c|}{$\begin{array}{c}\text { Sistim } \\
\text { Drainase }\end{array}$} & $\begin{array}{c}\text { Jenis } \\
\text { Bangunan }\end{array}$ & $\begin{array}{c}\text { Kala Ulang } \\
\text { (tahun) }\end{array}$ & $\begin{array}{c}\text { Tinggi } \\
\text { Jagaan }(\mathbf{m})\end{array}$ \\
\hline 1. & Sungai & Jembatan & 100 & $\geq 1,00$ \\
\hline 2. & Saluran & $\begin{array}{l}\text { Box, Jembatan } \\
\text { Kecil }\end{array}$ & 50 & $0,50-1,00$ \\
\hline 3. & $\begin{array}{l}\text { Catch Basin }< \\
0,30 \mathrm{~km}^{2}\end{array}$ & Pipe Culvert & 10 & Tak Ada \\
\hline 4. & $\begin{array}{l}\text { Road Surface } \\
\text { Drainage }\end{array}$ & Channel & 5 & $0,20 \mathrm{H}_{\text {air }}$ \\
\hline
\end{tabular}

Saluran-saluran drainase DAS Jatimulya telah diinventarisir agar lebih mudah untuk perencanaan menampung beban drainase sesuai perencanaan. Tabel 3. merupakan hasil inventarisasinya.

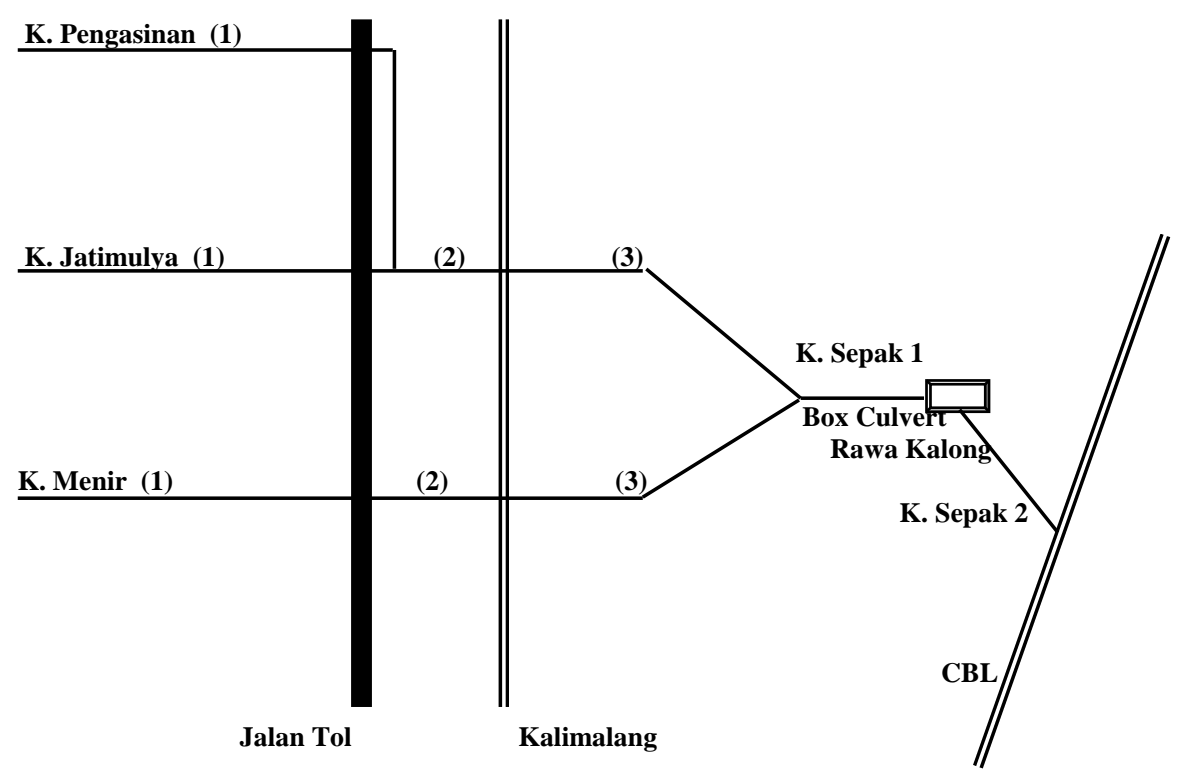

Gambar 1. : Skema Sistim Drainase Jatimulya 
Tabel 3. : Saluran-saluran Drainase DAS Jatimulya Bekasi

\begin{tabular}{|c|l|l|c|c|c|}
\hline No & \multicolumn{1}{|c|}{ Nama } & \multicolumn{1}{|c|}{ Segmen } & $\begin{array}{c}\text { Panjang } \\
(\mathbf{m})\end{array}$ & $\begin{array}{c}\text { Lebar } \\
(\mathbf{m})\end{array}$ & $\begin{array}{c}\text { Tinggi } \\
(\mathbf{m})\end{array}$ \\
\hline 1 & K. Pengasinan & & 765 & 2,20 & 1,00 \\
& K. Jatimulya & Sampai Dengan Jalan Tol & 450 & 3,00 & 1,20 \\
& K. Menir & & 685 & 2,80 & 1,00 \\
\hline \multirow{2}{*}{2} & K. Pengasinan & Dari Tol Sampai Dengan & 374 & 2,20 & 1,30 \\
& K. K. Menir & Kalimalang & 284 & 2,80 & 1,10 \\
\hline \multirow{2}{*}{3} & K. Pengasinan & Dari Kalimalang Sampai & 1.455 & 2,50 & 1,50 \\
& K. K. Menir & Dengan Pertemuan K. Sepak & 2.107 & 2,80 & 1,30 \\
\hline \multirow{2}{*}{4} & K. Sepak 1 & Dari K. Sepak Sampai Dengan & 3.737 & 4,30 & 1,70 \\
& & Box Culvert Rawakalong & & & \\
\hline \multirow{2}{*}{5} & K. Sepak 2 & Dari Box Culvert Rawa Kalong & 6.293 & 5,00 & 2,10 \\
& & Sampai Dengan CBL & & & \\
\hline
\end{tabular}

Dalam pengukuran saluran, dibedakan menjadi 3 segmen yang dibedakan berdasarkan kriteria masalah yang terjadi di lapangan, mengenai struktur bangunannya. Pembagian tersebut adalah sebagai berikut :

a. Segmen sebelum memotong jalan tol.

Sebelum memotong jalan tol, terdapat 3 saluran yaitu Kali Pengasinan, Kali Jatimulya dan Kali Menir.

Kali Jatimulya berawal dari Perumahan Jatimulya yang memotong jalan tol, kemudian bergabung dengan Kali Pengasinan. Kali Pengasinan berawal di wilayah Naragong (wilayah Kota Bekasi), yang kemudian melalui wilayah Kabupaten Bekasi di Jalan Raya Pengasinan sebagai batas wilayahnya.

b. Segmen antara jalan tol dan sebelum memotong saluran Kalimalang.

Pada segmen ini, saluran menjadi dua yaitu Kali Pengasinan yang bersatu dengan Kali Jatimulya serta Kali Menir.

Kedua saluran tersebut memotong Kalimalang melalui siphon menuju jalan Negara dan ke Kali Sepak. Saluran Kali Pengasinan dan Kali Menir mengalir memotong jalan Negara dan jalan kereta api bertemu di daerah Perumnas 3 yang merupakan awal Kali Sepak.

c. Segmen Kali Sepak.

Kali Sepak merupakan saluran yang akan meneruskan semua aliran dari kawasan Jatimulya menuju saluran CBL (Cikarang Bekasi Laut) dimana terus mengalir sampai Laut Jawa. 
Saluran Kali Sepak ini dibagi menjadi dua segmen, segmen satu mulai dari pertemuan Kali Pengasinan dan Kali Menir sampai box culvert Rawakalong (kawasan pemukiman) dan segmen dua setelah box culvert Rawakalong sampai CBL. Pada segmen dua ada tambahan debit dari saluran Kali Sasak (kawasan Margahayu, Kota Bekasi).

Permasalah utama yang ada pada Kali Pengasinan adalah terjadinya pendangkalan pada salurannya, banyaknya sampah serta box culvert yang memotong jalan tol kurang besar.

Kali Jatimulya hanya merupakan saluran yang hanya berfungsi mengalirkan sebagian beban drainase Perumahan Jatimulya menuju Kali Pengasinan. Permasalahan yang ada pada Saluran Kali Jatimulya adalah :

a. Banyaknya saluran tertutup di kawasan Jatimulya, sehingga menyulitkan dalam pemeliharaan atau pengerukan sedimen pada salurannya.

b. Box culvert yang memotong jalan tol kurang memenuhi kapasitas aliran.

Permasalahan saluran Kali Menir yang mengalirkan beban drainase seluas $3,64 \mathrm{~km}^{2}$, adalah sebagai berikut :

a. Terjadinya pendangkalan saluran setebal $0,50 \mathrm{~m}$ dari dasar saluran.

b. Banyaknya sampah yang menumpuk pada beberapa bagian saluran.

c. Box culvert yang ada dimensinya kurang mampu untuk mengalirkan beban drainase yang memotong di bawah jalan tol.

d. Syphon yang ada tidak mampu mengalirkan beban drainase yang memotong saluran Kalimalang.

e. Dimensi nsaluran belum mampu untuk mengalirkan beban drainase sebesar Q50th.

f. Banyaknya bangunan yang ada pada badan saluran.

Kali Sepak merupakan muara dari saluran Kali Pengasinan, Kali Jatimulya dan Kali menir, sehingga harus mampu untuk mengalirakan beban drainase dari ketiga saluran tersebut ditambah dengan beban drainase dari DAS Kali Sepak 
sendiri. Selain itu ada tambahan beban drainase dari Kali Sasak. Diperkirakan beban drainase yang harus dibebankan pada Kali Sepak sekitar 27,25 km². Adapun permasalahan drainase yang harus dibebankan ke Kali Sepak adalah :

a. Ada jembitan yang sempit yang kurang mampu mengalirkan beban drainase.

b. Banyaknya penyempitan pada tampang melintang saluran.

c. Tambahan beban drainase dari Kali Sasak.

d. Mahalnya pembebasan lahan untuk pelebaran saluran.

\section{Analisis Desain}

Dalam menghitung debit banjir rencana dari data hujan yang ada, dapat dibuat bagan alir sesuai Tata Cara Perhitungan Debit Banjir dari Standar Nasional Indonesia.

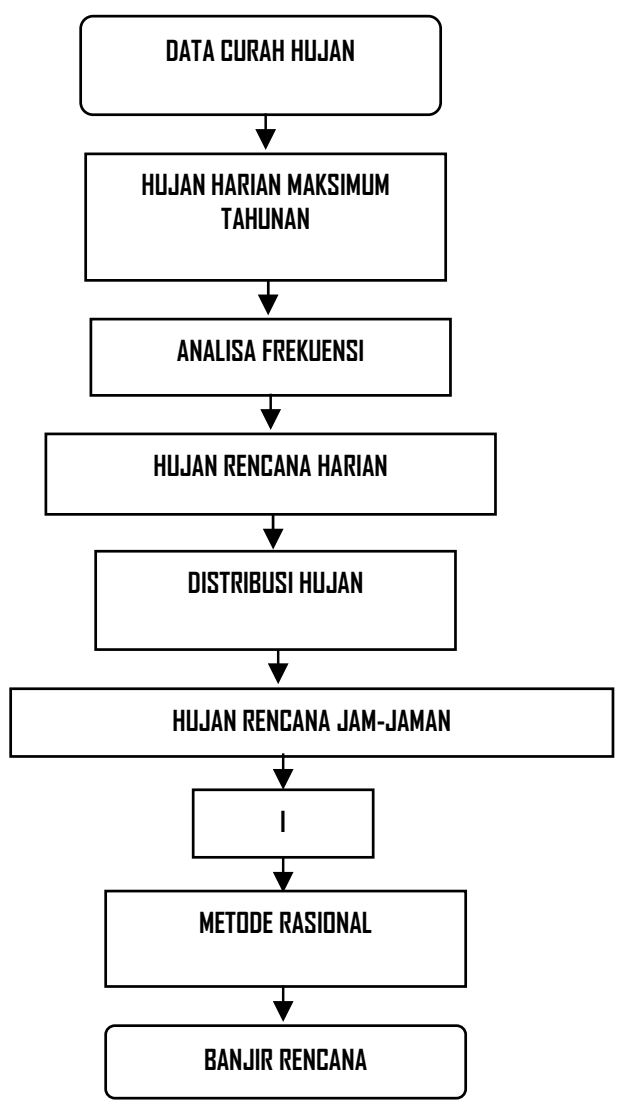

Gambar 2 : Bagan Alir Perhitungan Debit Banjir Rencana 
Untuk menghitung debit banjir rencana, dapat digunakan data hujan rencana yang dihitung dengan metode Log Pearson III. Data hujan diambil dari Stasiun Bekasi (02078A) pada lokasi $6^{0} .16^{\prime}$ LS dan $107^{0} .00^{\prime}$ BT, dengan elevasi 20.00 MSL.

Tabel 4. : Hujan Maksimum Tahunan Kabupaten Bekasi

\begin{tabular}{|c|c|c|}
\hline No. & Tahun & $\begin{array}{c}\text { Hujan Maks. } \\
(\mathbf{m m})\end{array}$ \\
\hline 1. & 1991 & 75 \\
\hline 2. & 1992 & 80 \\
\hline 3. & 1993 & 96 \\
\hline 4. & 1994 & 79 \\
\hline 5. & 1995 & 71 \\
\hline 6. & 1996 & 104 \\
\hline 7. & 1997 & 90 \\
\hline 8. & 1998 & 59 \\
\hline 9. & 1999 & 63 \\
\hline 10. & 2000 & 112 \\
\hline 11. & 2001 & 73 \\
\hline 12. & 2002 & 119 \\
\hline 13. & 2003 & 47 \\
\hline 14. & 2004 & 111 \\
\hline & & \\
\hline
\end{tabular}

Hasil dari analisis hujan Log Pearson III untuk hujan rencana 50 dan 100 tahunan dapat disajikan seperti pada Tabel 5. di bawah ini.

Tabel 5. : Hasil Analisis Hujan rencana Dari Stasiun Bekasi

\begin{tabular}{|c|c|c|}
\hline No. & $\begin{array}{c}\text { Kala } \\
\text { Ulang }\end{array}$ & $\begin{array}{c}\text { Hujan rencana } \\
(\mathbf{m m})\end{array}$ \\
\hline 1. & 50 & 207 \\
\hline 2. & 100 & 228 \\
\hline
\end{tabular}


Berdasarkan curah hujan rancangan, dapat dihitung intensitas hujan selama waktu konsentrasi $\left(t_{c}\right)$, dengan menggunakan rumus Mononobe.

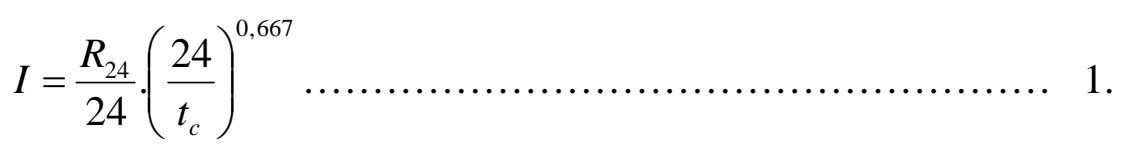

Dimana :

$$
\begin{aligned}
& I=\text { intensitas hujan }(\mathrm{mm} / \mathrm{jam}) \\
& R_{24}=\text { hujan rancangan harian }(\mathrm{mm} / \text { hari }) \\
& t_{c} \quad=\text { waktu konsentrasi }(\mathrm{jam})
\end{aligned}
$$

Sedangkan besaran untuk waktu konsentrasi dapat dihitung dengan rumus dari Dep.PU KP-01, sebagai berikut :

$$
t_{c}=0,86 \cdot L \cdot Q^{-0,20} \cdot i^{-0.4}
$$

Dimana :

$$
\begin{aligned}
t_{c} & =\text { waktu konsentrasi }(\text { jam }) \\
L & =\text { Panjang saluran atau sungai }(\mathrm{km}) \\
Q & =\text { Debit aliran }\left(\mathrm{m}^{3} / \mathrm{det}\right) \\
i & =\text { Kemiringan rata-rata dasar saluran }
\end{aligned}
$$

Setelah didapat Intensitas hujan, untuk perhitungan debit banjir rencana dipakai rumus rasional seperti berikut :

$$
Q=\frac{1}{3,6} \cdot C \cdot I \cdot A_{0}
$$

Dimana :

$$
\begin{aligned}
& Q=\text { debit banjir rencana }\left(\mathrm{m}^{3} / \mathrm{det}\right) \\
& C=\text { koefisien limpasan permukaan } \\
& I=\text { Intensitas hujan rencana }(\mathrm{mm}) \\
& A_{0}=\text { Luas daerah yang didrain }\left(\mathrm{km}^{2}\right)
\end{aligned}
$$


Untuk menghitung dimensi saluran drainase yang direncanakan (sesuai banjir rencana), dipakai rumus Strickler :

$$
Q=A \cdot V=k \cdot A \cdot R^{2 / 3} \cdot S^{1 / 2}
$$

Dimana :

$$
\begin{aligned}
& Q=\text { debit banjir rencana }\left(\mathrm{m}^{3} / \mathrm{det}\right) \\
& A=\text { luas tampang basah aliran }\left(\mathrm{m}^{2}\right) \\
& V=\text { kecepatan aliran }(\mathrm{m} / \mathrm{det}) \\
& k=\text { angka kekasaran Strickler } \\
& R=\text { jari-jari hidrolis }(\mathrm{m}) \\
& S=\text { kemiringan dasar saluran }
\end{aligned}
$$

Dari hasil hujan rencana, dapat dihitung debit banjir rencana untuk saluran sebesar 50 tahunan dan bangunan air yang ada di saluran dengan periode ulang 100 tahunan. Hasil perhitungan banjir rencana dapat disajikan pada Tabel 6 .

Tabel 6. : Hasil Perhitungan Banjir Rencana

\begin{tabular}{|c|l|c|c|c|}
\hline No. & Nama Saluran & $\begin{array}{c}\text { Periode } \\
\text { Ulang }\end{array}$ & $\begin{array}{c}\text { Hujan Rencana } \\
(\mathrm{mm})\end{array}$ & $\begin{array}{c}\text { Qrenc. } \\
\left(\mathrm{m}^{3} / \mathrm{det}\right)\end{array}$ \\
\hline 1. & K. Pengasinan & 50 & 207 & 18,66 \\
& 100 & 228 & 21,28 \\
\hline 2. & K. Menir & 50 & 207 & 13,88 \\
& & 100 & 228 & 15,51 \\
\hline 3. & K. Sepak 1 & 50 & 207 & 43,94 \\
& & 100 & 228 & 49,10 \\
\hline 4. & K. Sepak 2 & 50 & 207 & 55,43 \\
& & 100 & 228 & 61,96 \\
\hline
\end{tabular}

Kemiringan saluran (S) dibuat sedemikian rupa sehingga pengendapan dan gerusan dasar sungai (scouring)dapat dihindari. Selain itu dibuat kemiringan dasar sungai mendekati kemiringan sungai yang sudah ada. 
Tabel 7. : Hasil Perhitungan Dimensi Saluran

\begin{tabular}{|c|c|c|c|c|c|c|c|c|c|}
\hline \multirow[b]{2}{*}{ No. } & \multirow[b]{2}{*}{ Nama Saluran } & \multicolumn{2}{|c|}{ Dimensi Sekarang } & \multicolumn{2}{|c|}{ Renc. $Q_{5 \text { th }}$} & \multicolumn{2}{|c|}{ Renc. $\mathbf{Q}_{25 t h}$} & \multicolumn{2}{|c|}{ Renc. Q50th } \\
\hline & & $\mathbf{h}(\mathbf{c m})$ & b (cm) & $\begin{array}{c}\mathbf{h} \\
(\mathbf{m})\end{array}$ & $\begin{array}{c}\text { b } \\
(\mathbf{m})\end{array}$ & $\begin{array}{c}\mathbf{h} \\
(\mathbf{m})\end{array}$ & $\mathbf{b}(\mathbf{m})$ & $\begin{array}{c}\mathbf{h} \\
(\mathbf{m})\end{array}$ & b (m) \\
\hline 1. & Kali Menir & 50 & $100-200$ & 90 & 500 & 100 & 500 & 155 & 500 \\
\hline 2. & Kali Jatimulya & 80 & $200-300$ & 80 & 300 & 90 & 300 & 130 & 300 \\
\hline 3. & Kali Pengasingan & $60-150$ & $200-500$ & 100 & 500 & 120 & 500 & 165 & 500 \\
\hline 4. & Kali Sepak 1 & $100-200$ & $300-500$ & 150 & 800 & 200 & 800 & 250 & 800 \\
\hline 5. & Kali Sepak 2 & $100-200$ & $300-700$ & 190 & 800 & 200 & 800 & 275 & 800 \\
\hline
\end{tabular}

Tabel 8. : Desain Dimensi Bangunan Air

\begin{tabular}{|c|c|c|c|c|c|c|c|}
\hline No. & Nama Saluran & $\begin{array}{c}\mathbf{Q}_{100} \\
(\mathrm{~m} 3 / \mathrm{det} \\
\text { ) }\end{array}$ & $\begin{array}{c}\text { HYang } \\
\text { Ada } \\
\text { (m) }\end{array}$ & $\begin{array}{c}\text { BYang } \\
\text { Ada } \\
\text { (m) }\end{array}$ & $\begin{array}{l}\text { HDesain } \\
\text { (m) }\end{array}$ & $\begin{array}{c}\text { BDesain } \\
(\mathbf{m})\end{array}$ & Ket. \\
\hline 1 & $\begin{array}{l}\text { S. Pengasinan } \\
\text { - Box Culvert Jalan Tol } \\
\text { - Siphon Kalimalang } \\
\text { - Jembatan Jalan Negara } \\
\text { - Jembatan Kereta Api }\end{array}$ & 21,28 & $\begin{array}{l}2,00 \\
2,00 \\
3,00 \\
3,00 \\
\end{array}$ & $\begin{array}{c}2,00 \\
2,00 \\
12,00 \\
10,00 \\
\end{array}$ & $\begin{array}{l}2,00 \\
2,00 \\
3,00 \\
3,00 \\
\end{array}$ & $\begin{array}{c}2 \times 5,50 \\
11,00 \\
12,00 \\
10,00 \\
\end{array}$ & $\begin{array}{l}\text { Ganti } \\
\text { Ganti } \\
\text { Tetap } \\
\text { Tetap }\end{array}$ \\
\hline 2. & $\begin{array}{ll}\text { S. Menir } \\
\text { - } & \text { Gorong }{ }^{2} \text { Jalan Tol } \\
\text { - } & \text { Syphon Kalimalang } \\
\text { - } & \text { Jembatan Jalan Negara } \\
\text { - } & \text { Jemabatan Kereta Api } \\
\end{array}$ & 15,51 & $\begin{array}{c}2 \times \varnothing 0,80 \\
2,00 \\
2,00 \\
3,00\end{array}$ & $\begin{array}{l}------- \\
2,00 \\
1,50 \\
3,00\end{array}$ & $\mid \begin{array}{c}2 \times \emptyset ́ 1,60 \\
2,00 \\
2,00 \\
2,00\end{array}$ & $\begin{array}{c}------- \\
8,00 \\
8,00 \\
8,00\end{array}$ & $\begin{array}{l}\text { Ganti } \\
\text { Ganti } \\
\text { Ganti } \\
\text { Ganti }\end{array}$ \\
\hline 3. & $\begin{array}{l}\text { K. Sepak } \\
\text { - Box Culvert }\end{array}$ & 61,96 & 2,40 & 3,00 & 3,00 & $3 \times 7,00$ & Ganti \\
\hline
\end{tabular}

Kecepatan aliran : V = $1 \mathrm{~m} /$ det

\section{Kesimpulan dan Saran}

\subsection{Kesimpulan}

a. Banyak pekerjaan pengerukan dan pelebaran saluran, agar sesuai dengan dimensi perencanaan.

b. Banyak pembebasan tanah untuk memperbesar badan sungai.

c. Bangunan air yang ada harus dibesarkan, karena dimensinya tidak mencukupi.

\subsection{Saran}

a. Untuk mempermudah pemeliharan saluran harus disediakan jalan inspeksi. 
b. Cepatnya perkembangan pemukiman harus disertai dengan jaminan kepastian hukum, agar perencanaan yang sudah ditetapkan tidak berubah lagi.

c. Perlu dibantu dengan sumur-sumur peresapan pada daerah yang berair tanah dalam, agar beban drainase tidak terlalu berat.

\section{Daftar Pustaka}

, (2006); Detail Engineering Design Penanganan Banjir Jatimulya,

Pemkab. Bekasi

Anonim, (2004); Tata Cara Perhitungan Debit Banjir, Badan Standarisasi Nasional Jakarta

Ari S., (2006); Drainase Perkotaan, sebuah Buku Kuliah FTSP Jayabaya Jakarta (non publikasi) 